research during the past year amounted to $425 l$. , while the corresponding grant in the United States of America (salaries and administration expenses being excluded in each case) was more than $150,000 l$. It is true that in both countries the local authorities also spend some money on agricultural experiments, but the same disproportion would probably be found between the respective amounts if the figures could be arrived at.

Are we to take it, then, that these figures represent the relative importance of the agriculture of the two countries, or does the larger figure indicate the greater need of the American farmer for experiment and investigation? The exact contrary is the case; in the British Isles we have to farm with dear land, dear labour, and a number of charges due to the proximity of a high civilisation. Farming in consequence can only pay when there is a considerable monetary return per acre, and the bigger yield necessary involves intensive cultivation, the purchase of fertilisers, and the employment of skill, which are all needless to our competikors on a virgin soil. But each increase in the expenditure and skill necessary for the crop means a greater opening for knowledge and investigation; science can do little to save money for the man who merely stirs the surface of a virgin prairie, scattering in the seed meanwhile, and then leaves it to take its chance until harvest. Compare with such a farmer the highly technical routine of the hop-grower who spends 5ol. per acre before he harvests his crop, his repeated cultivations, his manurings, his sprayings for various ends; it is with this kind of crops that science can find profitable employment.

Looking at the average yields of the various countries of the world, we find that Great Britain is the most intensively farmed country; it obtains the biggest crops per acre, it has to spend the most to obtain them. Furthermore, the biggest crop the greater are the risks of disease and blight, the greater are the difficulties in securing high quality. Here, then, in Great Britain exists the greatest need for knowledge and investigation; we cannot even always beg knowledge from wiser countries, for many of our problems are special, and brought about by the very conditions of high farming which prevail here. England was the first country to start an experimental station, ye Rothamsted still remains the only institution solely devoted to agricultural research in the British Isles, if we except the farm of the Royal Agricultural Society at Woburn. The income of the Rothamsted station, derived solely from private benefaction, is about $2600 \mathrm{l}$. a year; in the United States each of the fifty-three States possesses a station receiving $3000 l$. a year from the Federal Government, besides what the State itself may contribute, in addition to the great central department of agriculture to which reference has already been made.

\section{SOME NEW METHODS IN METEOROLOGY.}

PROF. BIGELOW has here collected six studies. The first four deal with diurnal periods:-(i.) of temperature; (ii.) of barometric pressure; (iii.) of vapour tension, electric potential, and coefficient of dissipation; (iv.) of terrestrial magnetism; (v.) treats of the variable action of the sun and its effects upon terrestrial weather conditions; whilst (vi.) is a general review of the status of cosmical meteorology.

The immediate occasion, the author tells us, for these studies was the necessity of deciding upon the best line of work for the new "Mount Weather" Observatory, at Bluemont, Va., which is intended to serve as a centre for research in connection with the U.S. Weather Bureau This observatory is to have on its staff experts in various departments, and there is to be an advisory committee, of which Prof. Bigelow is described elsewhere as chairman.

Several of Prof. Bigelow's views as to the prosecution of the higher meteorology have much to recommend them as, for example, the following :- "If cosmical meteorology is to be established then all rough and ready method must be abandoned, and the work of computing and dis cussing the data must be placed in the hands of physicists

1 "Studies on the Diurnal Periods in the Lower Strata of the Atmosnhere." Reprints from the Monthly Weather Review, 1905. By Prof Frank Hagar Bigelow. (Washington: Weather Bureau, 19=5.) NO. I 938, VOL. 75$]$ and astro-physicists who possess scientific instincts and training" (p. 48); or again :- "We must waste nothing by using bad methods of work and unskilled men " (p. 5i). But Prof. Bigelow possesses, apparently, a duality in his nature, and the following are examples of his second self :"In the midst of this concatenation of forces the terrestrial magnetic field stands out as the best unifier or integrator. It is the most sensitive and delicate pulse which we possess, having one throb in the solar mass, and the other in its synchronism with the earth's meteorological elements" (p. 48). This seems not unworthy of Colonel Starbottle addressing a jury, but what exactly does it mean? Here, again, is what we are told of the sun :"Recent computations indicate that at the centre.. there is a nucleus which ... is nearly as solid as the interior of the earth, with a temperature of about $10,000^{\circ} \mathrm{C}$. ; the average density . . . is $\mathrm{I} \cdot 43$ times that of water, and this is located at half the distance from the centre to the surface" (p. 39).

Feeling doubts of our capacity to follow with advantage Prof. Bigelow's highest flights, we have devoted more attention to his studies on the diurnal variations. The view to be taken of these must depend on whether they are intended as examples of the methods to be followed by the Mount Weather Observatory, or whether they are simply illustrations of the "rough-and-ready" methods the abandonment of which the author elsewhere recommends. Study i. deduces from continuous temperature records at Blue Hill Observatory, and from observations made during or in connection with kite ascents there, the diurnal variation of temperature at a series of heights for every month of the year. The final results are embodied in Figs. I4 to 25 , the diurnal variation being assumed negligible at the height of 3400 metres the whole year round. The original data are not given, and the methods of manipulating them are only indicated generally. Of the probable value of the results no estimate seems possible. Study ii. gives some general, but not very lucid information about the diurnal variation of barometric pressure. Of the amplitude of the 24 -hour term it says, not incorrectly, "it is very different at neighbouring stations." Yet Prof. Bigelow obtains Fourier coefficients for a composite diurnal inequality based on data from Boston, New York, Washington, Buffalo, and Cleveland. Again, we are told in the general remarks that the amplitude of the 24-hour term is from one-fourth to onehalf that of the 12-hour term. But in the composite case treated by Prof. Bigelow the 24 -hour term is larger than the 12 -hour term in the summer months, and the arithmetic means from the twelve monthly values of the amplitudes seem closely alike for the two waves.

In the calculations, the diurnal variation is assumed to be completely accounted for by three waves of periods 24 12, and 8 hours. If [n] denote the departure at hour from the mean for the day, then the contributions to $[n]$ from the $12-$ and 8 -hour waves are respectively

$$
\frac{1}{2}\{[n]+[n+12]\} \text { and } \frac{1}{3}\{[n]+[n+8]+[n+16]\} \text {, }
$$

and what remains after subtracting these two contributions from $[n]$ is assumed to represent the contribution of the 24-hour wave. This method cannot be recommended even for rough preliminary work, unless the 24 -hour term is largely dominant and the Fourier series is known to converge very rapidly. In the present instance the amplitude of the 8-hour wave is, according to Prof. Bigelow's figures, about half that of the 24-hour wave from November to February. In these months the observational data would certainly give an appreciable 6-hour term. The same method is then applied to the diurnal variation of temperature (with sign reversed) as deduced in Study $i$. for heights of 195,400 , and 1000 metres at Blue Hill. The results for the 8-hour wave at 195 metres during the summer months at once arrest attention. In July, for instance, no hourly value assigned to this wave is positive. This seems to be due, not to misprints-though these are somewhat numerous in the tables-but to error in the figures for the diurnal inequality itself. If the twenty-four hourly differences from the mean are summed algebraically, there is in most months a substantial remainder, showing that the mean value for the day has not been correctly taken.

Limits of space allow only of brief reference to other 
matters. Tables iii. to vi., p. 23, and numerous curves deal with diurnal variation of vapour pressure at Parc St. Maur, and at Blue Hill at several levels. Tables vii. and viii. and Chart xii. deal with electric potential at Greenwich for each month of the year, and with seasonal data at Perpignan and Paris. From a study of these the author advances in Chart xiii., sect. ii., as the representative curve of the diurnal inequality one possessing five maxima! A very similar curve-based on results by Zölss and Gockel--is given for electric dissipation. The conclusions embodied in these curves cannot be recommended for general acceptance. The same remark applies to the conclusion; on p. $2 \mathrm{I}$, that "the (earth's) electrostatic field varies inversely to that of the solar energy." The sole basis for this view seems to be Table ix., p. 24 , and Fig. 53, which are regarded as proving a parallel variation from year to year between the number of solar prominences and the reciprocal of a quantity supposed to represent the mean annual potential gradient at Greenwich.

The diurnal variation of the magnetic field seems to be ascribed to up and down movements of positive ions in the atmosphere; these are supposed to indulge a preference for cold air during the day. As to magnetic storms, the author's theory is even less clearly stated, but he apparently regards it as supported by the rapid rise towards I p.m. in the frequency figures given by Mr. Maunder for the hour of commencement of magnetic storms at Greenwich from 1882 to 1903 . The author is presumably unaware that Mr. Maunder has since attributed this sudden rise to a cause having nothing to do with terrestrial magnetism, and that it is not shown in figures he has given for the epoch 1848 to 188 I (cf. Phil. Mag., September, 1905, p. 306). In opposition to the theory advanced by Prof. Schuster and others, that the magnetic diurnal inequality is due to electric currents in the upper atmosphere, the author contends that the. source is more directly thermal and confined to the lowest two miles of the atmosphere. A comparatively short series of simultaneous observations at suitably chosen high-and low-level stations should be fairly decisive for or against Prof. Bigelow's contention.

In the above criticisms the author has been regarded as a scientific man whose aim is to convey scientific ideas to other scientific men. If his aim is simply to convey to an unscientific public a general idea of the problems which present themselves in cosmical physics, with the view of impressing the imagination rather than of appealing to the intelligence, the case is no doubt different. But on either hrpothesis, what useful purpose is likely to be served by the indiscriminate collection of statistics and the enunciation of vague, hasty theories? A sparing use of theory may serve as a lubricant, but theory when heaped upon theory is simply dust clogging the wheels of science.

Charles Chree.

\section{UNIVERSITY AND EDUCATIONAL} INTELLIGENCE.

Mr. J. J. WeLch has been appointed to the newlyestablished chair of naval architecture at the Armstrong College, Newcastle.

IT is announced in the Lancet that the late Dr. Gustave Schorstein bequeathed $500 l$. to the regius professor of medicine at the University of Oxford for the pathological department of the medical school, 50ol. to the London Hospital, and a sum, which will probably amount to some ro,oool., in trust to the University of Oxford, subject to certain life interests. When these are expired the capital is to be at the disposal of the University for use as the University may think fit.

THE following courses of lectures for teachers have been arranged, among others, at University College, London, in conjunction with the education committee of the London County Council :- "The Teaching of Geography to Children," Prof. Lyde; "Some Types of Vegetation and the Conditions under which they Exist," Dr. Fritsch, both courses beginning on January 17 ; and "The Principles of Electrical Science during the Past iso Years," Prof, Trouton, beginning on January 19.

$$
\text { No. } 1938 \text {, VOL. } 757
$$

THE preliminary programme of the second International Congress on School Hygiene, to be held on August 5-10, 1907, at the University of London, South Kensington, has been issued. The work of the congress will be divided into eleven sections, each presided over by an authority on the subject dealt with. The organising committee is inviting educational and public health authorities, universities, colleges, schools, societies, and others to appoint delegates to the meeting, and is appealing for donations to meet the large expenditure involved in organising the congress, which it is estimated will be not less than $3000 l$. The president of the congress is Sir Lauder Brunton, F.R.S., and the hon. secretaries are Dr. James. Kerr and Mr. E. White Wallis.

THE report of the Board of Education for the year 1905-6 is of an encouraging nature. There is plenty of evidence provided that our national system of technical education continues steadily to improve. The report points out that much attention has been paid throughout the country to the extension and improvement of the facilities provided for continuative education. There has been marked activity in the establishment of courses of instruction affording special technical training, and the effective character of the many courses organised under varied conditions shows that local circumstances have received the consideration necessary for success in this kind of educational work. Technical institutions affording wholetime training for those who can give two or more years to study after completing a secondary-school course have improved and multiplied their courses of technical instruction. The multiplication of courses requiring the whole time of students is a gratifying indication of the growing appreciation of the value of the work of the technical school; but this appreciation is not confined to whole-time instruction. The improved organisation of the varied institutions engaged in supplementing the training which a youth receives in the office or workshop has borne fruit in many practical developments, demonstrating the extent to which such further education may become a recognised element in the lives of our youths. The report, which runs to 106 pages, deals fully with every department of elementary, secondary, and technical education, and shows conclusively that, political controversy notwithstanding, valuable work is being accomplished in the schools.

\section{SOCIETIES AND ACADEMIES. LONDON}

Royal Society November 22.-. "The Structure of Nerve Fibres." By J. S. Macdonald. Communicated by Prof. C. S. Sherrington, F.R.S.

Nerve fibres teased in harmless saline solutions and examined under the microscope exhibit a series of varied appearances which are distributed in a constant order in the length of the fibre. This orderly distribution is explained as due to the electrical current which traverses the fibre inwards from each injured point, and which leaves the fibre to traverse the salt solution at certain definite " kathodal" points.

At each injured point, the source of the current, the colloid material is precipitated and is surrounded by an aqueous solution. By the use of definite reagents the solution is found to be a concentrated solution of a potassium salt, probably potassium chloride. The author in a previous paper has directed attention to the importance of this fact, when injury is considered as the fatal consequence of a violent " excitation," and to the probability that " excitation" is the outcome of such a desolution of colloid material and liberation of inorganic salt to diffuse and give rise to electrical change. At kathodal points a similar set of conditions is observed, in origin secondary to those already described at the current source.

The injury region is abruptly limited by an adjacent " anodal region," where the material of the nerve fibre has an exceptionally fluid appearance, except in so far as this fluidity is disturbed by secondary acid formation and diffusion.

The anodal region passes into the kathodal region through a graduated series of coagulative change, attended 